\title{
Implementation of customisation strategies in collaborative networks through an innovative Reference Framework
}

\author{
Rosanna Fornasiero, Andrea Zangiacomi, Valentina Franchini, João Bastos, \\ Americo Azevedo \& Andrea Vinelli
}

To cite this article: Rosanna Fornasiero, Andrea Zangiacomi, Valentina Franchini, João Bastos, Americo Azevedo \& Andrea Vinelli (2016): Implementation of customisation strategies in collaborative networks through an innovative Reference Framework, Production Planning \& Control, DOI: 10.1080/09537287.2016.1188428

To link to this article: http://dx.doi.org/10.1080/09537287.2016.1188428

曲 Published online: 31 May 2016.

Submit your article to this journal $₫$

山 Article views: 10

Q View related articles $\sqsubset$

View Crossmark data \lceil 


\title{
Implementation of customisation strategies in collaborative networks through an innovative Reference Framework
}

\author{
Rosanna Fornasiero ${ }^{a}$, Andrea Zangiacomi ${ }^{a}$ (D) Valentina Franchini ${ }^{b}$, João Bastos ${ }^{c}$, Americo Azevedoc and Andrea Vinellib \\ aITIA-CNR, Milano, Italy; 'bTG, Università degli Studi di Padova, Vicenza, Italy; ' INESC TEC, Faculdade de Engenharia da Universidade do Porto, Porto, \\ Portugal
}

ABSTRACT

Consumer needs and expectations of specific target groups - such as elderly, obese, disabled or diabetic persons - are arising as challenging opportunities for European companies which are asked to supply innovative customised goods of high quality at affordable price. This is particularly true in the fashion as well as in the orthopaedic sector where there are many different competences to conjugate to offer dedicated products to the mentioned target groups. This paper aims at proposing a reference model to support companies in defining collaborative supply networks for customised production. In particular, this work describes the implementation of the developed model in a real case highlighting the changes implied at network level to address the need for fashionable and healthy products.
ARTICLE HISTORY

Received 2 August 2014 Accepted 16 April 2016

KEYWORDS

Customisation; personalisation; collaborative networks; fashion companies; supply chain management

\section{Introduction}

Recent years have stressed the need of re-inventing the enterprise concept and the way to achieve competitive advantage. Enterprise managers are now forced to address market and especially individual customers by putting more emphasis on the service levels they provide, by reducing response times and by tackling customers' specific needs. This confluence of trends has led managers moving from a traditional functional-focused approach in the way they conduct business into a more holistic one addressing the overall supply chain. As a consequence, it is emerging at industrial level the adoption of collaborative strategies for the production of high-customised complex products with increased emphasis in the service levels and the reduction of the response time. Along this vein, consumer needs and expectations of specific target groups - such as elderly, obese, disabled or diabetic persons - are arising as challenging opportunities for European companies which are asked to supply innovative and fashionable goods of high quality, affordable price and eco-compatible in short time and with high service levels.

The main objective of this work is to propose an innovative Reference Model for collaborative networks and its implementation in a real case in the fashion sector, through re-engineering of Business Processes, to support the production of goods addressing the needs of specific consumer target groups. The aim of the proposed reference model is to support and guide companies in modelling, designing and configuring the combination of processes, functions, activities, relationships and paths along which products, services and information flow in and among companies.
The approach to define and implement the reference model is composed of three main steps highlighted in Figure 1. The first step is the development of the Reference Model Framework according to decisional levels and structural dimensions suggested by literature analysis, the second one consists in the cross-case analysis on the specific sectors under consideration, namely footwear and orthopaedic sectors, to define best practices necessary to guide model implementation and the third is its instantiation to support a Collaborative Network in the realisation of customised products according to target groups needs.

In the specific customised manufacturing case addressed in this work, the cross-case analysis represented a fundamental phase. The implementation of the new business model for customisation, in fact, calls for the identification of specific trans-sectoral practices which can be identified only through a preliminary analysis and a comparison between two sectors, as the footwear and the orthopaedics, where there are some complementary competencies to face the problem of customised production of fashionable and healthy products. Generally speaking, cross-case analysis is not a compulsory step. Different implementation cases dealing with contexts where practices to be applied are already explicit and clear may not include it.

The work has been organised in the following way: after the analysis of the state-of-the art on demand-driven supply networks in Chapter 2, Chapter 3 presents the Reference Model Framework proposed. In Chapter 4, the cross-case analysis on fashion and orthopaedic footwear sectors used to build the model is described, moreover, Chapter 5 illustrates the implementation of the model in a real case. 


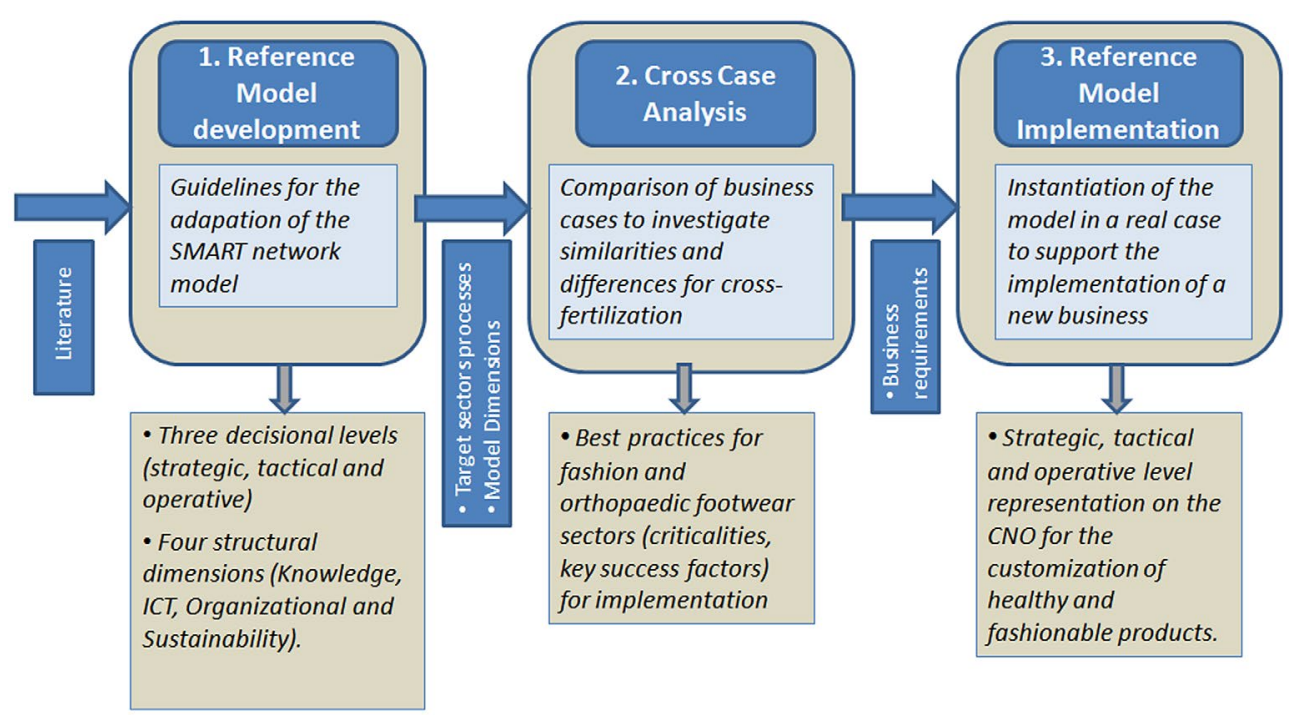

Figure 1. The research approach for implementation.

\section{Literature review}

Nowadays, competition within the fashion sector is among global networks and the key issues are on how to develop and implement innovative managerial models and methods to support collaborative practices, especially among SMEs, which represents the majority of companies in TCFI. (Dyer and Singh 1998; Camarinha-Matos, Boucher, and Afsarmanesh 2010).

A new level of complexity is arising, given the fact that competition as well as collaboration schemes are transitioning from company versus company, to supply network versus supply network. As a consequence, the management of both interorganisational and inter-supply chain processes and information is becoming even more critical in order to assure rapid responses, eco-sustainability and quality assurance of products and processes. Linked with this reality, existing studies show that supply chain integration increases performance especially in scenarios with high complexity. In these high supply complexity environments, specific integration practices and means are required in order to address the increasingly complex customer demand. (Gimenez, van der Vaart, and van Donk 2012)

The acceleration of globalisation, and rapid technological evolution are leading to increased unpredictability and instability. The emergence of global markets is forcing companies, SMEs in particular, to adapt to a new competitive environment in order to proactively respond to challenging market requirements with increased responsiveness and flexibility (Fornasiero and Zangiacomi 2013).

This reality is intensified by the fact that consumer goods, in particular innovative and fashion products, have in the last decades been facing an increased number of product variants with a dramatic reduction of products life-cycle. Furthermore, paradigms such as mass customisation and personalisation are forcing companies to increase flexibility in order to produce small batches, till one-of-a-kind product, to satisfy customer demand (Bastos et al. 2012).

Recent research in the field of supply networks addressed different forms of business networks. They are distinguished, for example, by the value chain orientation (horizontal, vertical, lateral), life span (long-term vs. short-term), degree of virtualisation or hierarchical structure (hierarchical vs. non-hierarchical networks) (Camarinha-Matos and Picard 2008; Grefen et al. 2009). The current market asks for flexible organisational structures, which quickly adapt to new business requirements and sustainability challenges. These new demands are forcing business networks to have shorter life-time existence and take advantage of new infrastructure technologies supporting distributed information systems and knowledge in order to be competitive and achieve high performance (Christiaanse and Kumar 2000; Zhang, van Donk, and van der Vaart 2011).

The paradigm of demand-driven supply networks is emerging in literature as a collaborative approach answering to consumer's needs and expectations (Childerhouse, Aitken, and Towill 2002; Piller and Tseng 2003; De Treville, Shapiro, and Hameri 2004; Boer and Dulio 2007; Yeung, Choi, and Chiu 2010). This implies different approaches to market based not only on traditional sales channels (as shops or retailers) but more and more on an Internet-mediated contact with consumers both for product conception and for sales. These highly integrated and dynamic supply networks rely intensively in new set of tools, methods and related services enabling the collaborative networking operation (Fornasiero et al. 2013).

In parallel, especially due to the recent advances in Information \& Communication Technologies (ICT), namely the internet support and social networking, collaborative networks and customer communities have shown an unprecedented growth in a large variety of forms. Customers are coming together in online communities, where they publish and share their products and services experiences, assessing the manufactures, vendors and service providers effectiveness (Romero and Molina 2011). Increasingly, consumers are participating both in the front-end period with contributions to the idea generation and conceptualisation, and the back-end period with involvement in the design and testing phases of new product development by enhancing the innovation process and thus co-creating value (Nambisan 2002; Romero, Molina, and Camarinha-Matos 2011).At the same time, the market increasingly values collaborative networks that 
endorse the sustainability challenges. Moreover, as Adler (2001) effectively discussed, the new enlarged/extended structures, characterised by high cognitive content exchanges, can no longer be coordinated by traditional hierarchy/market instruments as they require trust to share knowledge and leverage on external, updated and complementary competencies.

More recently, the work of Carter and Rogers (2008) has identified four supporting facets, or facilitators of the Sustainable Supply Chain Management (SSCM), which are: strategy, risk management, organisational - culture and transparency. From the perspective of sustainability, the research literature identifies basically two distinct strategies for SSCM practices (Seuring and Müller 2008): supplier management for risks and performance assessment; supply chain management for sustainable products (mainly in the green/environmental aspects).

After a deep analysis of some of the most important supply network reference models in literature - among others, the Value reference model (VRM 2007), the Supply-Chain Operations Reference model (SCOR) and the Y-Cim model - the SMART model proposed by Filos and Banahan (2001) has been selected as the starting point to map practices to be implemented at different levels along the following three main dimensions:

(1) Knowledge dimension: to map partners' competencies to be shared within the network in terms of products and processes;

(2) ICTs dimension: to support the requirements for the implementation of ICT services at different process levels along the network;

(3) Organisational dimension: to provide specifications of the organisational changes for SMEs for structuring supply networks .

The SMART model represents in fact a comprehensive alternative which both includes relevant aspects of other models, such as ECOLEAD (Romero and Molina 2009) and is also targeted on collaborative networks. The three dimensions above listed have been identified in the model as key aspects to be managed for networked companies. It also enables to avoid the high level of complexity which characterises the formalisation of other models, as the SCOR, especially when dealing with SMEs. For the scope of this study, a new dimension, coherent with the eco-efficiency objective, has been added to the model, namely Sustainability. This dimension is intended to support companies aiming to create sustainable networks, in developing an eco-compatible approach for their products and processes.

A fundamental question for SC design in the fashion sector deals with the strategies to be used to provide the right products and services to the different consumer groups identified. In today's always changing market conditions, the correct choice of the SC strategy is crucial for companies in order to be able to better serve and satisfy increasingly demanding customers. Moreover, the choice of the SC strategy should be based upon a careful analysis of the demand characteristics of the various product/markets served by a company especially in a fashion-based sector (Christopher, Peck et al. (2006). On the other hand Bruce, Daly, and Towers (2004) have addressed the SC management in the textiles and clothing industry characterising textiles and apparel as volatile markets, with short product lifecycles and high product variety. From the Fisher (1997) framework, the textiles and apparel products fall in the class of innovative products with unpredictable demand and yet, the textile sector has extremely low profit margins so that producing and even holding small quantities of stock is not commonly a viable option. Therefore, companies in the sector have to produce products rapidly to fulfil orders. This poses a challenge to $\mathrm{SC}$ managers. According to this context, Bruce et al. have stressed the need of future research in order to further understand SC management for fashion and commodity manufacture and supply.

Lee (2004) refuted the concept that the holy grails of SC management are high speed and low cost arguing that the best SC management policy should be based on agility, adaptability and alignment. Agility enables the SC to respond to short-term changes in demand or supply quickly. Adaptability requires that SC evolves over time enabling companies to adjust their structure, strategies, products and technologies to meet market changes. Finally, Alignment highlights the need that firms member of SCs align interests of all participants with their own sharing incentives and responsibilities to improve performance of the entire supply chain.

More recently, Berasategi, Arana, and Castellano (2011) proposed a comprehensive framework for collaborative innovation. The proposed framework, includes a reference model, a set of analysis tools and a methodology for implementing the collaborative networked innovation processes within a Collaborative Networked Organisations (CNO). The model consists of two interrelated components: the activity model which describes the activities organised into focus areas, which should take place in the innovation network; and the actor model, which defines the participation scenarios of the actors within the network (Berasategi, Arana, and Castellano 2011).

Likewise, Loss presented an agile business model as an approach to support collaborative networks. Taking into consideration the agile perspective to the business model approach, the authors proposed a theoretical framework to address the agile perspective of future business models where complexity and adaptability are crucial. Namely, they addressed the organisational perspective through the business models in accordance with the business processes and the social dimension through the enhancement of the collective knowledge and the value cocreation (Loss and Crave 2011).

On the other hand, starting from the perspective of planning and supporting the implementation of SSCM strategies, the SCOR model (SCC 2010) is a major framework for supply chain planning that features supply chain management practices and business process reengineering. With version 10.0 of SCOR, the model includes process elements addressing environmental aspects of managing a supply chain called GreenScor. These additions allow the SCOR model to be used as a green supply chain management tool.

\section{Reference Model Framework}

The Reference Model Framework proposed in this paper aims to support fashion companies in defining collaborative networks for the production of customised products and is instantiated for the specific case of customisation towards healthy and fashionable products. Figure 2 presents the overall conceptual view of this model mapping its three decisional levels (strategic, tactical and operative) with the four structural dimensions considered (knowledge, ICT, organisational and sustainability). 


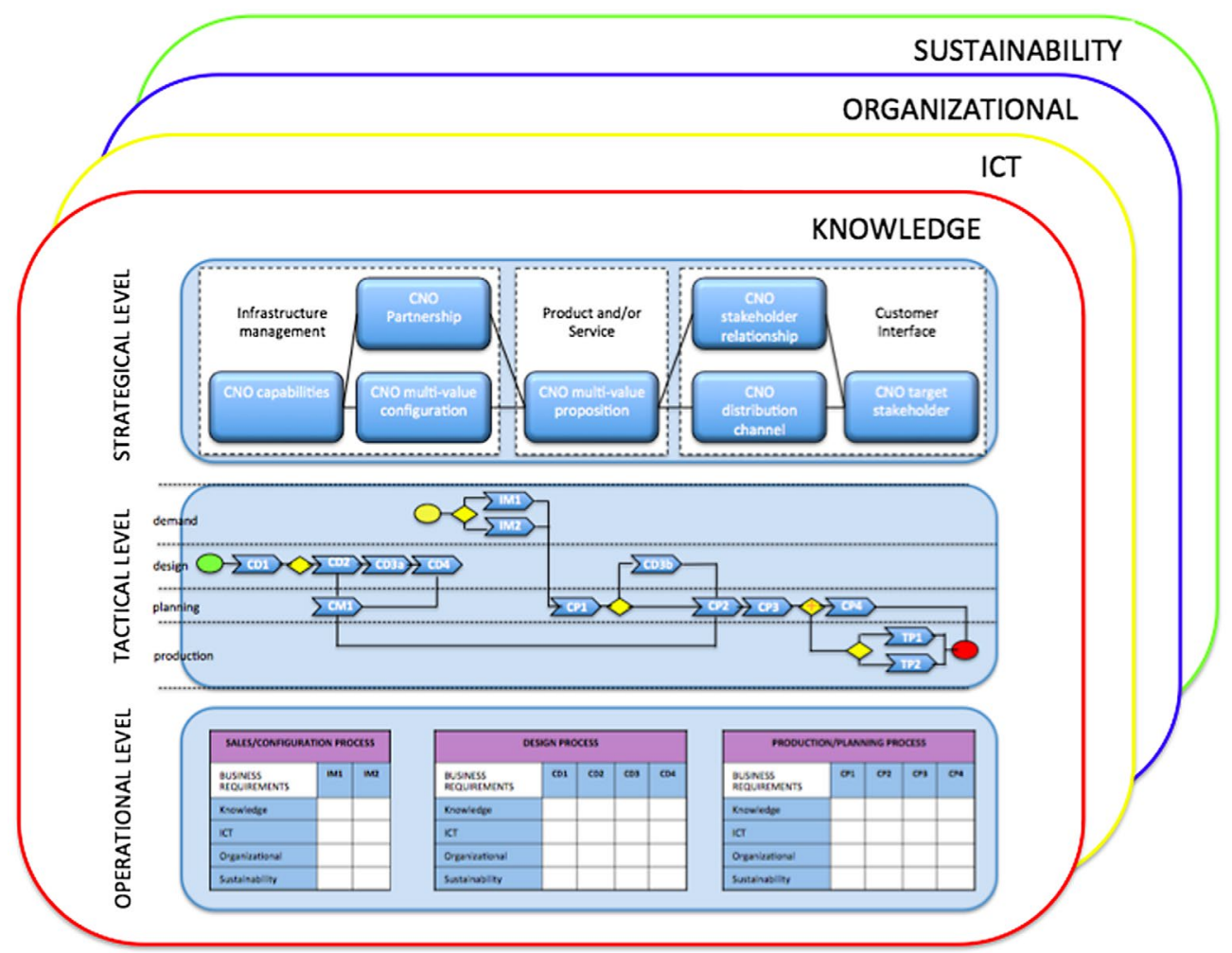

Figure 2. Reference Model Context Diagram.

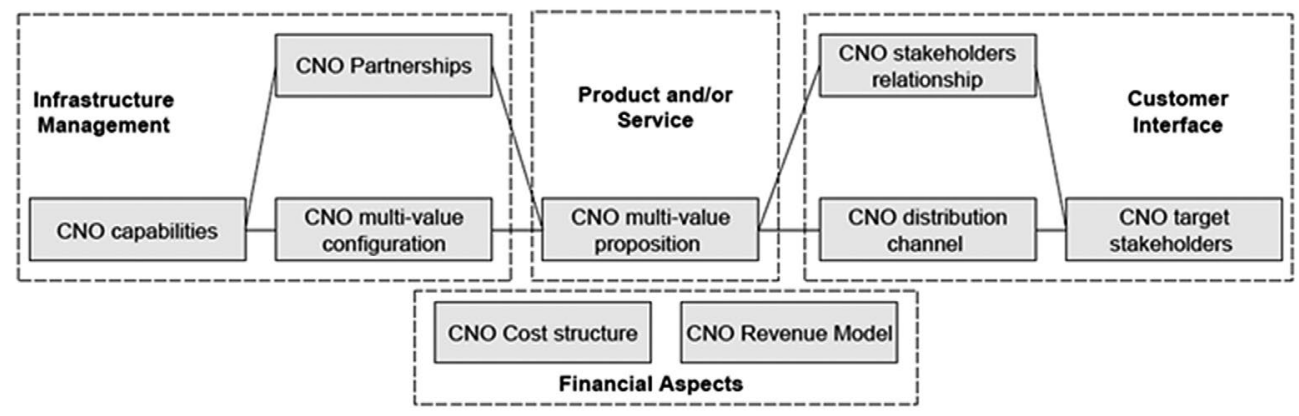

Figure 3. Definition of Collaborative Networks strategy based on building blocks. Source: Loss and Crave (2011).

For what concerns the strategic level, the business model framework proposed by Osterwalder and Pigneur (2010) is used as a way to map the most important building blocks that influence the definition of the value proposition of a company and, in particular, the extension of the model proposed by Loss and Crave (2011) is useful for the application to the collaborative networks (Figure 3).

As underlined in Romero and Molina (2011), this kind of modelisation is useful for CNO to facilitate the combination of the capabilities of their members creating new abilities to better support the personalisation of experiences and create real personal value propositions based on synergies with customer.

\subsection{Guidelines for instantiation of the reference model}

The reference model can be used as a guideline by consultants and companies to change the SCM processes towards collaborative network paradigm. The application of the reference model starts with the elicitation of the building blocks by the management board of CNO companies to handle with the strategic level. They are asked to answer to a list of questions through brainstorming sessions to define their 'CNO multi-value proposition' and then the other building blocks consulting their collaborators. They should define the building blocks related to 'CNO partnerships' and 'CNO multi-value configuration' with support of supply chain managers or the 'CNO distribution channels' with marketing managers. Financial aspects are also important and need to be fixed and agreed at the very beginning especially when many different companies are involved. The process might be iterative and require several steps before reaching a formal agreement among the partners of the CNO.

Once the strategies of the CNO are defined, companies can work at the tactical level of the Reference Model, to identify the most important critical processes for the defined value 
Table 1. Characteristics of the firms selected from fashion and orthopaedic footwear sectors.

\begin{tabular}{|c|c|c|c|c|c|c|c|c|}
\hline & A & C & $\mathrm{D}$ & $\mathrm{E}$ & G & I & M & $\mathrm{N}$ \\
\hline Sector & Fashion & Fashion & Fashion & Fashion & Orthopaedic & Orthopaedic & Orthopaedic & Orthopaedic \\
\hline Company dimension (turnover) m€ & 43 & 820 & 50 & 100 & 15 & 4.6 & 1.7 & 70 \\
\hline Company dimension (staff) & 96 & 17,500 & 135 & 374 & 70 & 45 (10 for shoes) & 18 (6 for shoes) & 100 \\
\hline Country & Italy & Portugal & Portugal & Italy & Italy & Portugal & Italy & Portugal \\
\hline
\end{tabular}

proposition. This activity can be held by the second level of management in the companies (supply chain manager, production manager, marketing manager, development manager) involved to define together the whole process flow, highlighting the sequence and the interrelations between the different subprocesses involved in each phase. Each sub-process is then further split in the related activities identifying the owner of each activity along the CNO. The formalisation can be done according to the Business Process Model Notation (BPMN) which can support business process management, both for technical and business users.

During formalisation of the business processes, the four structural dimensions of the model need to be explicited and all related aspects defined: the knowledge to be used and exchanged for each activity (in terms of documents and transfer of information from one actors to another), how to organise the activities among the actors, which ICT tools are required to enhance collaboration in the network and where sustainability issue is mostly important.

The definition of the operative level guides companies in the specific implementation of the business processes with practices to handle activities, KPIs for assessment of activities, templates, information and materials useful to support the processes. The elicitation of the operative level allows to put in practice all the actions necessary for the successful implementation of the customisation paradigm.

\section{Cross-case analysis}

In order to conceptually structure and validate the model framework addressing supply networks for fashionable and innovative products, it was necessary to collect and evaluate relevant field data and perform specific industrial case studies in different sectors and scenarios. This research approach based on empirical fieldwork enables to address both qualitative and quantitative data useful, as already underlined, to identify specific transsectoral business requirements necessary to guide the model implementation in the specific selected real case.

\subsection{Methodology for cross-case analysis}

The companies selected for the cross-case analysis are from the footwear sector and have been selected both among large companies and SMEs to analyse practices that can be transferred and applied to SME networks. The sample was created adopting theoretical sampling (Glaser and Strauss 1967), and multiple investigators have been used to reduce bias and produce more reliable data (Eisenhardt 1989; Yin 1994; Pagell 2004; Eisenhardt and Graebner 2007).

In particular, the sample selection has been guided by the need to compare fashion footwear and orthopaedic footwear companies, bridging the capability of the former to manage fashion aspects through style and design with the experience of the latter in acquiring functional requirements from customers belonging to specific target groups. For each sector, four representative companies have been selected in Italy and Portugal according to their attitude in implementing the two main objectives addressed by the proposed Reference Model. The companies, in particular for what concerns the orthopaedic ones, have been also chosen due to their capability to realise different kind of products and for the representativeness of the adopted processes. Most of these firms, both SMEs and large companies, are in fact already known for best practices in their specific sector. In Table 1, a short overview of the analysed firms is provided. The four main dimensions of the reference model (knowledge, ICT, organisational and sustainability) have been considered to understand the main characteristics of the sectors also in terms of strength and weakness.

For each selected company, an 'AS IS' business process analysis was conducted through focused interviews, supported by plants visits to gain a thorough understanding of the processes involved, and BPMN representation to collect and formalise a rich set of data, both qualitative and quantitative. Interviews have been conducted with the most relevant representatives of specific roles and function levels in the network, as in particular, supply chain managers, purchasing managers, sales managers and operations managers in order to gather different perspective and reach a comprehensive vision on implemented practices. Furthermore, the requirements of each company were pointed out and analysed in detail to draw the relevant characteristics, procedures and techniques along the supply network. The authors conducted all the interviews and two researchers attended each meeting. The interviews were all transcribed to integrate the notes and observations written during the meetings. Within-case analysis allowed to understand and describe single company requirements in terms of the four dimensions, while a cross-case analysis among the different companies of the same sector, allowed to compare companies' behaviours and understand collaboration mechanisms. According to the best practices arisen from the analysis of companies considered in the two sectors, it was possible to bring out the differences and similarities between their supply networks and highlight most important features that should be implemented in collaborative networks for the realisation of product customised on the basis of specific target group needs. In the following paragraph, the cross-case analysis developed for each sector of interest is reported.

\subsection{Fashion and orthopaedic footwear sectors cross-case analysis}

As already underlined above, the fashion sector is characterised by volatile product demand and need of quick planning and 
Table 2. Best practices from cross-case analysis for fashion and orthopaedic footwear sectors.

Fashion footwear secto

Orthopaedic footwear sector

\section{Organisational}

Sales/configuration process

- A high level of product customisation (based both on aesthetic and functional features) to face competitively the market for the 'best fit' approach

Design process

- Long-term relationships are established with suppliers which are involved in the design phase and during product industrialisation: each of them has to develop a specific component according to the information received by the shoe producer

- Suppliers provide both standard components and exclusive products (i.e. soles and heels can be patented)

Production planning process

- Several phases of the production processes are commonly outsourced like cutting, stitching

- Third parties are involved for the final assembly

Production process

- Companies develop a strong relationship with their outsourcers as well to guarantee the highest quality level to their customers and benefit from their availability and flexibility along the season

- Shoes are realised in smaller production lots according to the implemented customisation level

Knowledge

Design process

- Innovation is strongly driven by knowledge in terms of:

- fashion trends

- technical and functional features of new materials and components and their application

- Design capabilities and know-how on production techniques represent an important competitive advantage for companies along the whole supply chain

- Need to coordinate different actors in order to put together specific competences for each footwear component

ICT

Design process

- Manufacturing processes are more and more supported by CAD-based design starting from the 2D drafts creation to the 3D development of models and sizes. The integration of CAD files from different suppliers using different software is still an open question

Production process

- Production phases, as laser cutting and leather marking, need to be integrated automatically with the design phase

- Real-time monitoring along networks is crucial for the efficient management of the suppliers

Sustainability

Production process

- Large enterprises have started to implement sustainable practices moving to eco-products and eco-processes (ex. Nike, Adidas, Timberland)
Sales/configuration process

- According to customer-specific needs, shoes are produced either made-tomeasure with a personalised last (Lot1) or selected with best fit approach among available standard models

- Due to the monopolistic advantage that orthopaedic providers can benefit in their territory, improvements on the downstream/market side are minor or neglected

Production planning process

- Production is outsourced to companies manufacturing in the orthopaedic sector and then customised in some aspects by the orthopaedic footwear company (i.e. insoles)

- Supply networks are organised to compress response lead times and improve quality of products, due to the specific and complex needs of patients

Production process

- Orthopaedic producers tend to establish strong partnerships with technology suppliers to improve and innovate their production processes and products in terms of lead-time quality

- Traditionally the production is handmade and craftsmanship is an important value-added to obtain the best quality and the best results for the patient

Sales/configuration process

- Focus especially on the acquisition and fulfilment of the functional requirements to answer effectively to patients' needs

- Limited list of products from which customers can usually chose their favourite model and materials

Design process

- Shoes are customised in structure and materials basing on customer's measurement or 'best fit' configured, according to pathology requirements

- Specific needs from past customers data collected and detailed studies of the pathologies aimed at obtaining the best corrective effects

- The orthopaedic technician merging patient's measures and requirements with medical indication, designs the specific shoes, according to the selected model

Sales/configuration process

- Foot measures can be taken using 3D scanners; in some cases, the 3D scanner allows to send information on the collected order directly to the product supplier; the plaster cast technique is still used for the most critical cases

Production planning process

- Information from 3D scanners can be sent directly to the milling machine for the production of the last

Production process

- Production is not supported by specific applications. Roughly $30 \%$ of the shoes are produced using personalised last. ICT-based solutions could be implemented in different stages of the process

Design process

- Orthopaedic providers are usually small and medium enterprises that implement (sometimes indirectly) sustainable practices mainly concerned with product characteristics: i.e. anti-allergic, anti-sweating and with no superficial treatments materials to avoid problems with foot skin production responses. Footwear in particular presents a really fragmented and rigid scenario, constituted by many specialised knowledge intensive companies most of the time grouped in industrial districts. Each phase of their production process is deeply characterised by traditional approaches always oriented to batch quantities and local maximisation (Piller and Tseng 2003).

Most of the literature on the orthopaedic footwear is related to clinical aspects of foot pathologies, discussing different types of resolution for them. However, there is a lack of studies regarding the analysis of the processes within orthopaedic companies and the best practices applied along the orthopaedic footwear supply network. This work starts focusing on their investigation.

Based on the previously defined four dimensions, the crosscase analysis for the fashion and orthopaedic sectors has been summarised in Table 2 according to the specific business process category implied. Results from the analysis represent the basis for the instantiation of the Reference Model on a real industrial case involving companies wishing to implement the addressed business, as described in the following chapter. 


\section{Implementation of the reference model: a case study}

In this chapter, the most important features of the reference model are described for a specific CNO composed of a subset of the firms considered in the cross-analysis previously presented collaborating with other companies. The CNO is in fact based on Company $\mathrm{A}$, a traditional firm willing to start the realisation of small lots of healthy and fashionable best fit shoes addressing the need of selected target groups like diabetic people. In order to implement the customisation of healthy and fashionable products, the collaborative network (core companies of the $\mathrm{CNO}$ ) of Company A includes new partners with strong competencies in the realisation of small series of best fit shoes for the addressed target groups. For this reason, experts in the field able to support the company in the design of shoes for this new market have been selected, in particular, an orthopaedic provider, represented by Company M. The choice of this partner among the other orthopaedic companies was influenced by the fact that it operates within the same footwear district of Company A in the centre of Italy and they already collaborate on the basis of specific needs from customers. In addition, other two partners have been also added: a technology provider to monitor the validity of the shoes produced for each customer (Company $\mathrm{O}$ ) and a laboratory for customisation (Company P) to manufacture the shoes in outsourcing. More details on the four companies and a description of their relationships and roles within the CNO are hereafter provided (see also Figure 4).

Company $\mathrm{A}$ is a worldwide company operating with own brand in the footwear fashion sector and producing highly refined shoes for woman. It covers mainly Italian and European markets $(80 \%)$; the production is around 500,000 pairs of shoes for the fall-winter and 250,000 for the spring-summer collection and is greatly affected by seasons and trends. The company network is composed of around 100 partners (both suppliers and outsourcers) and the customers (distributors) are more or less 2500. The average dimension of an order of a model from an existing collection is around 100 pairs of shoes. If a customer (retailer) asks for the realisation of a customised model variant, the minimal dimension for the customised order is 5/600 pairs of shoes; the customisation nowadays regard only aesthetical and material configurations.

Company M is an Italian SME producing customised orthopaedic products such as shoes, lower limb and foot orthotics, corsets and prosthetics. Company B supports Company A in detecting and properly formalising functional requirements of the shoe models, identifying also the proper correlation between requirements and shoe specification and sustaining the personalisation and customisation of important shoe components. In addition, it is in charge of the design and manufacturing of fully personalised insoles which represent the functional component of the shoe.

Company $\mathrm{O}$ is specialised in the design and manufacture of innovative electronic devices for health, sports and industrial markets; the main product developed is a gait analysis medical device that provides quantitative and qualitative information regarding users' dynamic plantar pressure. This tool can be used by Company A through a web platform, namely the Foot Measurement Platform, to support the sales process gathering important data on customer walk used for the selection of the most appropriate shoe and to personalise specific insoles and to monitor the validity of the shoe produced.

Company $P$ is divided into a design department, that defines the style idea of the personalised shoe or of the Engineering-To-Order

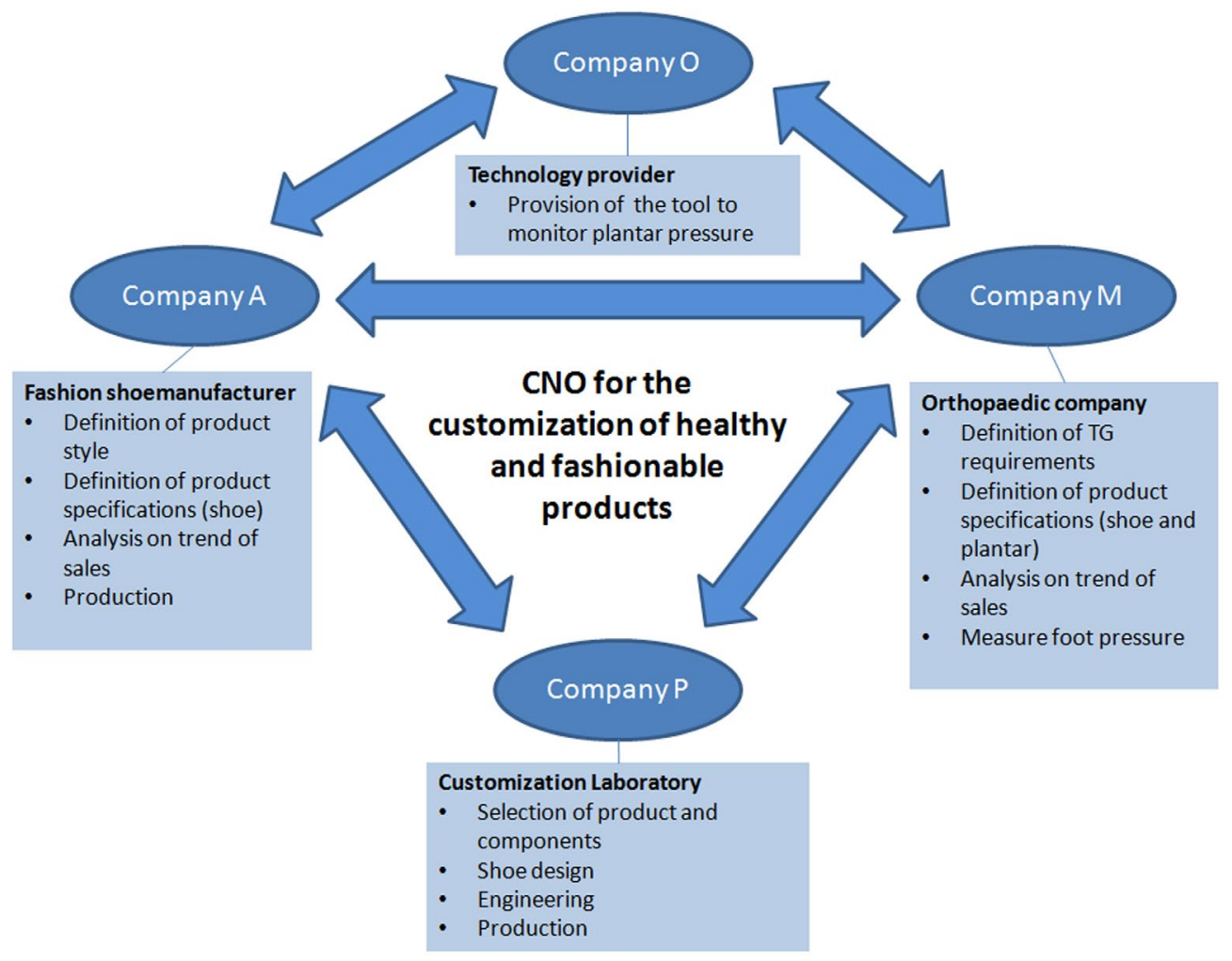

Figure 4. The CNO partners and their mutual relationships and roles. 
collections and realises the CAD model and the prototype, and a production department, that realises the shoe/small series. The company $\mathrm{D}$ can give a strong contribution to product personalisation during the production phase thanks to innovative product process.

\subsection{Strategic level}

In Table 3, a short summary of the most important characteristics related to the building blocks of the new business model is depicted for the considered network as a guideline for companies of the fashion sector. For each building block, it is shortly described which are the dimensions to be involved in the process.

\subsection{Tactical level}

The tactical level has been then instantiated to the selected CNO according to specific requirements and needs collected and analysed with Company A and the other partners of the CNO. Here, the BPMN diagram applied to the analysed footwear scenario is represented in Figure 5. The picture highlights the flow of the processes, the actors involved as well as the tools used.

An innovative aspect considered in the new process flow proposed to the $\mathrm{CNO}$ is the capability to involve the customer (even end-consumer) during product design and configuration and the strict collaboration both with suppliers and technology providers all along the process flow. It follows a short description of each process as it is conceived for the specific CNO. For each process, a general overview on the four dimensions of the model is given.

The collaborative design, development and customisation of products are composed of four different macro-processes: CD Design process, IM - Sales/configuration process, $\mathrm{CP}$ - Production Planning process and TP - Production process.

The first process is CD1, Market analysis process, where the network is supported in the identification of trends and TG needs. The use of a Knowledge Management Tool (KMT) for market trends analysis enables data gathering from the Company B database and subsequent data mining in order to identify needs and trends from the distribution of past sales to guide Company $A$ and $B$ in the creation of the new collection of shoes and related customised footbeds in CD2, Collection definition. Here, the Collaborative Design Environment (CDE) enables the four actors to interact and share their specific expertise in the definition of a new collection targeted on the identified consumer groups of diabetics. At this point, it is relevant to manage and formalise several parameters important for design choices. The CD3 process is doubled in two different ones related to product design and both supported by the CDE. CD 3-A (Product design with CAD modelling) is related to the creation of the technical models of all collection's variants. Main aspects are related to product design and interference with material type and implementation of a proper configuration space for product variants, including sizing. Also sustainability aspects as competencies on eco-materials and eco-design practices for green product innovation are here considered. All these aspects are managed through the Quality Monitoring (QM) tool. This process is also supported by the Life Cycle Assessment tool (LCA) in order to integrate environmental reflections in design and production choices. CD3-B (Product design based on customisation) is activated when dealing with personalised orders and represents the customisation process where the designer of Company $D$ has to implement customer's choices and specific measures modifying CAD models of the shoe defined in CD3-A and the designer of Company $B$ has to do the same for what concerns the personalised footbed.

Last process concerning product design is CD4 - Process planning support and is aimed at defining all the information on product manufacturing, as BOM and working cycles, on the basis of knowledge on resource capacities and supplier specific data and considering implied sustainability issues concerning, for example, green manufacturing, reverse logistic, environmental awards and ISO certification. This process is also strictly related to Partner search and selection (CM1). Here, possible partners are identified through the Partner Search (PS), a tool supporting network configuration and integrating knowledge on quality, flexibility, reliability, costs, responsiveness and sustainability of the different partners. It supports the assignment of production phases and materials purchase according to specific Key Performance Indicators (KPIs), matching requirements and needs defined in CD2 for the new collection, in order to create the best network to fulfil customer orders. At this level, the Collaborative Planning tool (CP) is first used to define preliminary agreements with network partners at the beginning of the season.

With IM1 sub-process, Direct product configuration, which consist in the direct sale of a product in a commercial site, it is possible for the customer to choose among the models of the small series and to customise the shoe in a Company B shop. The customer interacts with the shop assistant to gather data and obtain its profile in terms of wishes and needs in order to properly select and configure a specific footwear. The CDE is here used to support the aesthetic personalisation through the presentation of the virtual model of the shoe, while the Foot Measurement Platform is used to evaluate plantar pressure to design the footbed.

When the collection creation is fully realised and orders have been collected, it is necessary to manage them in CP1 - Customer Order Processing. During this step, orders are analysed and validated and administrative information are split from technical data.

In CP3 - Collaborative Production planning, the production orders schedule is negotiated between partners according to an iterative process through the Collaborative Planning tool. An important criteria for the selection of the best plan is the partner availability, allowing to make quick adaptations and handle possible production exceptions. At this point, production orders can be launched in TP2 Production process for customised shoes and the realisation and personalisation of shoes takes places by Company D and its network through advanced technologies as the Laser engraving machine. Also production of personalised footbeds is here realised by Company $B$.

The CP4, Partner monitoring and control, runs in parallel to TP2 in order to assure production monitoring and control both from quality and sustainability side: the Quality Monitoring Service (QM) provides a set of $\mathrm{KPI}$, including environmental performance indicators, to assess the quality level of products and of the internal and external production phases. This allows the planning of possible corrections and provides useful information that can be stored and distributed at different levels to the various stakeholders. 


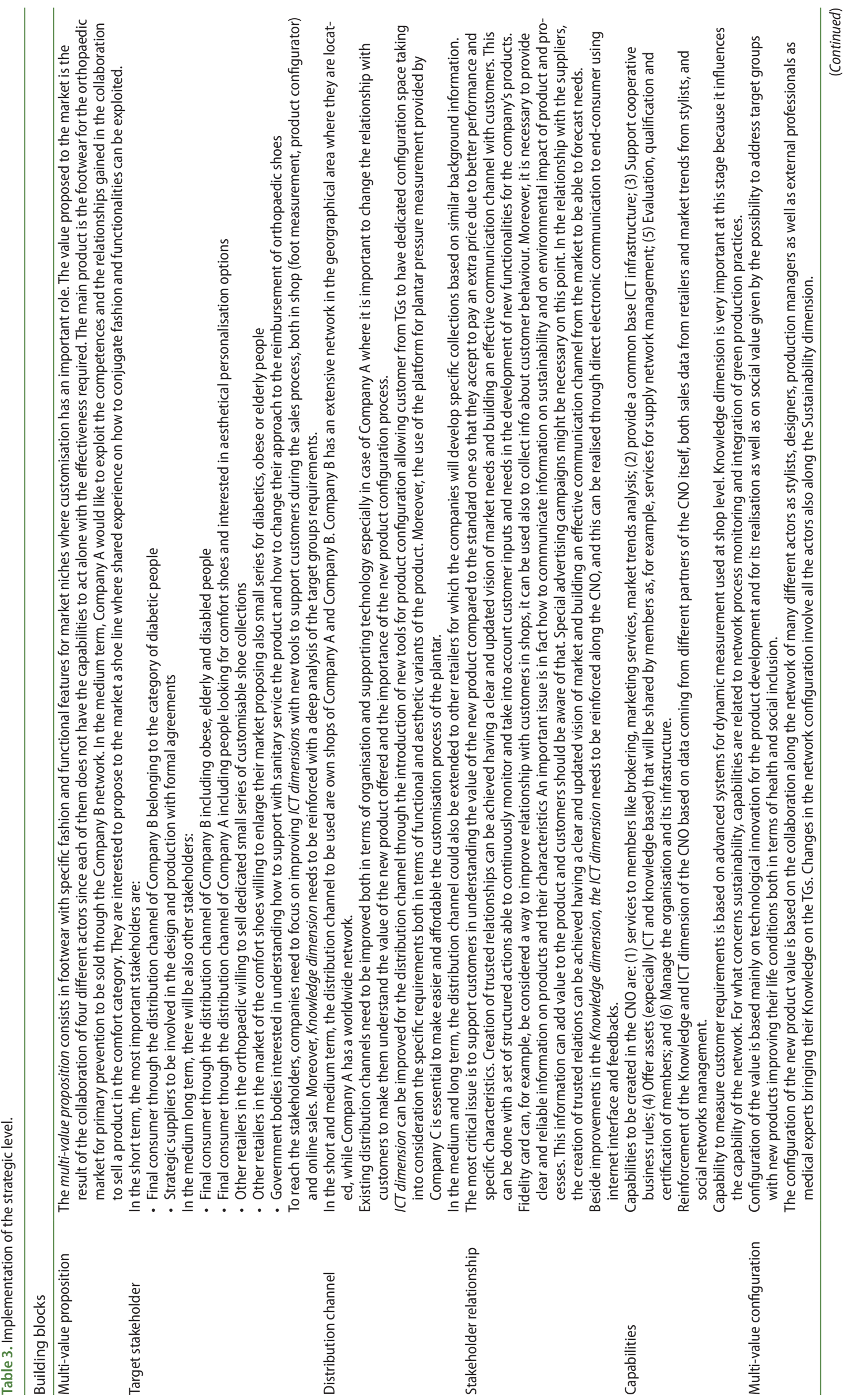




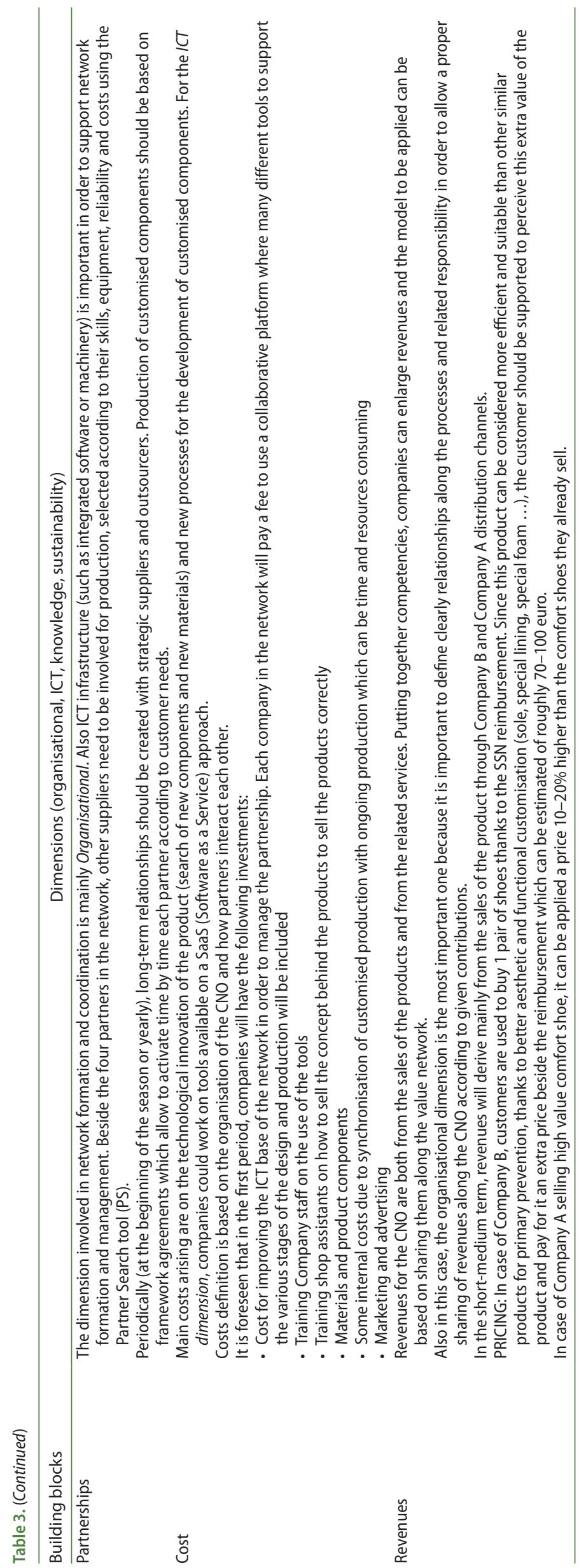




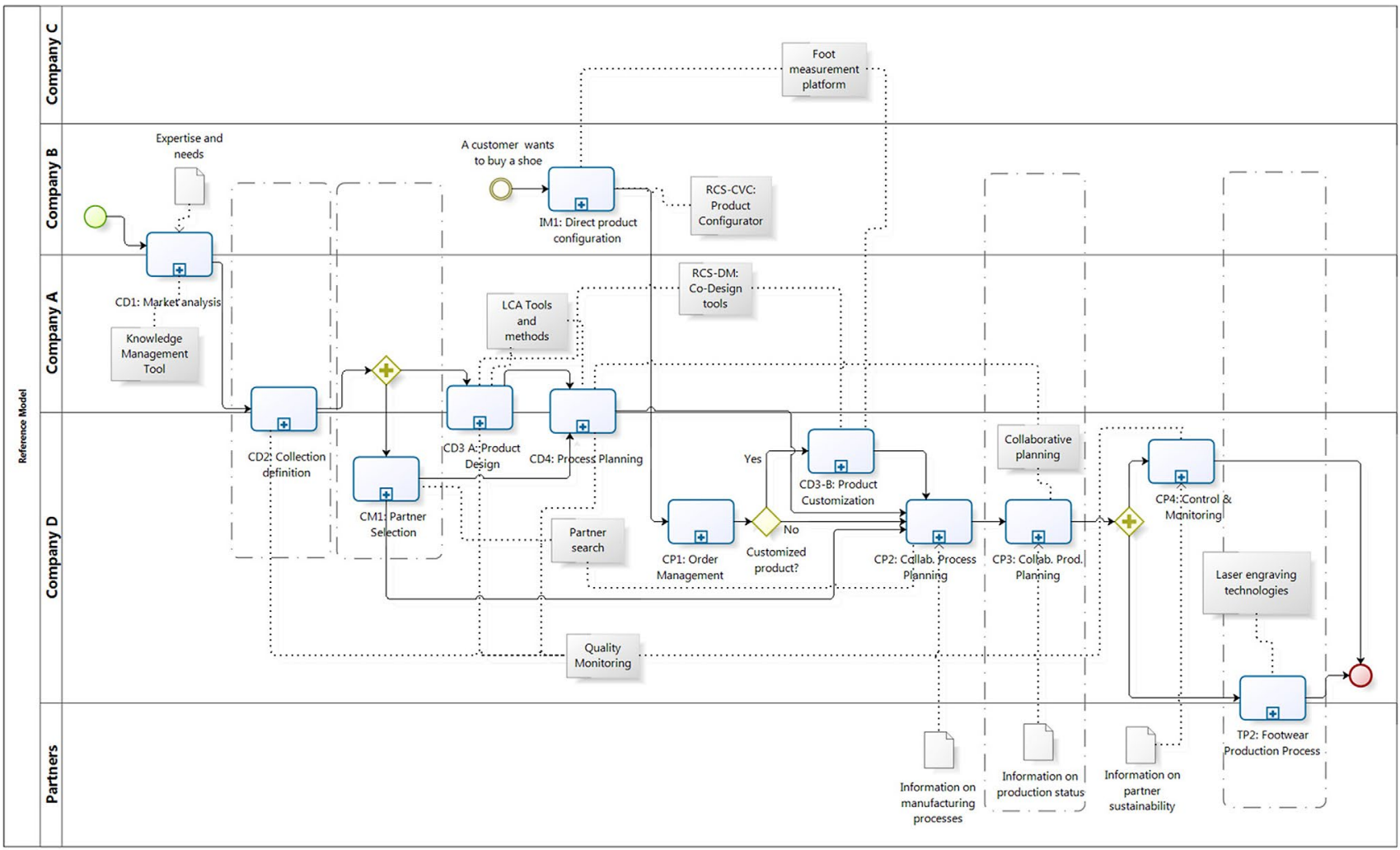

Figure 5. Instantiation of the tactical level of the model.

\section{Conclusions}

This work proposes a RM framework to create innovative collaborative environments enabling fashion companies to produce and deliver small series of specialised and customised high value-added products. The industrial and empirical nature of the RM framework guarantees full applicability of its guidelines.

In particular, the RM represents a formalisation of a methodology that can be applied to companies as a way to enable a revision in the organisation of their business strategy by the application of innovative methods and tools for product design, planning, production activities as well as rapid manufacturing technologies. The Reference Model aims to facilitate supply networks in managing consumers' data to understand their needs, involve them in product design and configuration, exchangerelated data through adequate data models and secure systems, collaborate with suppliers, implement innovative manufacturing machines, monitor product quality and sustainability. The model has been applied to the real case of a fashion company willing to enter a new niche market. The instantiation applied according to the three different levels of the RM started with the definition of the new Business Model and the description of the most relevant dimensions involved in its application concerned with the strategic level. The model enables a revision and a formalisation of the main business processes at the tactical level and provides operative support to this processes.

For what concerns the specific implementation in the considered business case, even if the collaboration processes are still under revision by the involved companies, some improvements have already been reported:

- increased level of coordination among partners (measured in terms of time spent to find a partner, time for quotation, ...);

- increased involvement of consumers including specific requirements in product design and configuration all over the supply chain (measured in terms number of customers involved in design phase, number of customisation managed, ...); and

- increased ability to monitor quality and eco-sustainability of products in the network (in terms of amount of information available on materials, production process and practices along the network).

The proposed Reference Model Framework represents a contribution towards the definition of adequate business models for the innovative and fashion products industry. In addition, it aims to provide the supply network managers of this sector with reference business process guidelines, to support them in decision-making at three time-framed decision levels: Strategic, Tactical and Operational.

The application of the RM was challenging: the experience put indeed in evidence the need of a cultural change to be introduced in the actual work habits and business values, which could bring to a renewed way to organise both the daily work and the longterm strategy where the improvement of the relationships in the production chain (both upstream and downstream) towards a collaborative model is based on a trustful cooperation. 
The application of the RM helped companies to define a fashion and functional footwear product as an attractive option to usual preventive shoes available in the market since most of the time preventive shoes offered from the SSN reimbursement can be rejected due to their aesthetical characteristics by people suffering from initial phase of diabetic pathology, thus vanishing the positive outcomes of adhering to a preventive behaviour from the beginning.

The experience derived by the application of the RM helped to understand and to identify some critical lack at methodological level, currently present in the shoemaking sector, even if targeted to healthy products. In fact, despite the strong and deep expertise and the availability of technology, the shoemaking value-chain is still characterised by an inadequate level of knowledge sharing, even when the information about the product is directed to the final consumer. The adoption of a framework like RM allows to start the formalisation of process flows both up- and downstream as a way to define in a second stage common data dictionaries and protocols for information sharing, toward a more cooperative industrial approach.

\section{Notes on contributors}

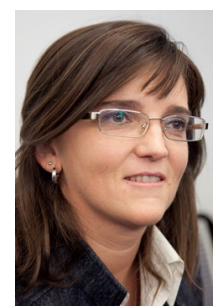

Rosanna Fornasiero is researcher at CNR-ITIA working in the area of Supply Chain Management, Mass Customization, Innovation management and Research policies. She has experience in many EU projects for fashion sector in different framework programmes (ICT, NMP, Growth, Industrial Leadership) both as scientific manager, technical coordinator and researcher. She was responsible for the IMS initiative YourGoods on international research activities on Consumer Goods. She works with industrial associations to support regional research projects and technologies transfer to SMEs. She is coordinator of the roadmapping group in the National Cluster of Intelligent Factories. She has more than 60 publications in scientific journals and conference proceedings and she is part of the scientific committee of conferences like PRO-VE, APMS, ICE.

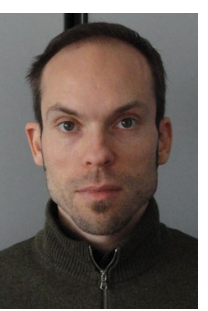

Andrea Zangiacomi is researcher at the Institute of Industrial Technologies and Automation of the Italian National Council of Research. He has a degree in Industrial Engineering and his research interests are related to supply chain management, collaborative networks and process modelling. These topics have been also applied to Mass Customisation scenario in national and EU-funded research projects. He has been involved in roadmapping activities at regional and national level. He also has a degree in Psychological Sciences with specialisation in Psychology of work and organisations. Interests in this field are mainly related to the impact of new technologies on organisations and interaction design.

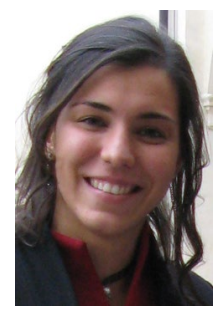

Valentina Franchini is a management engineer graduated in 2009 at University of Padua. She obtained a PhD degree with a thesis on Supply Network Management, developed as a result of her collaboration to the European 7th framework program project 'CoReNet', coordinated by ITIA-CNR. In 2013 she got her MBA degree at Collège des Ingénieurs (Paris) - Scuola di Alta Formazione al Management (Turin), where she focused on startups' and innovation's topics, developing a business acceleration program for Fondazione Agnelli. She worked as a consultant for several companies in different industries, such as Industries spa, Philip Morris International and many Italian SMEs. Nowadays she works as a Manager at Artsana group, coordinating multiple projects in innovation and business development matters.

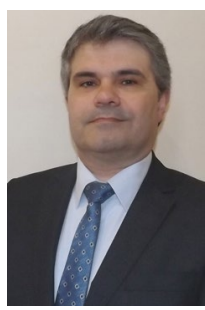

João Bastos is an associate professor in the Department of Mechanical Engineering at ISEP - Polytechnic Engineering Institute of Porto. His areas of teaching are supply chain management, distributed planning and collaborative networks. Currently, his research is related with the knowledge management on customised networked manufacturing environments and he has been active in preparing and participating in $R \& D$ projects involving academia and industrial companies. He has been the author of several articles in international journals and technical publications, attending national and international conferences and participating in several scientific programmes committees. Presently, he is a project manager researcher at INESC TEC (applied research Institute - formerly INESC Porto.

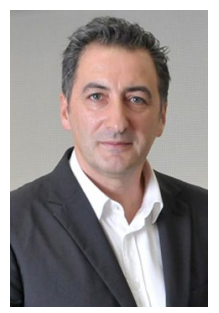

Americo Azevedo is an associate professor in the Department of Industrial Engineering and Management at Faculty of Engineering of University of Porto (FEUP). His research and teaching focuses on operations management, business processes management and enterprise collaborative networks. He teaches in the academic programmes of FEUP and PBS (Porto Business School) and in specific programmes such as EDAM (Engineering Design and Advanced Manufacturing) of the MITPortugal Program. He has been author of many articles in international journals and technical publications and also active in preparing and participating in R\&D projects involving industrial companies. He has been the reviewer and evaluator of several international R\&D Industrial projects and a member of several scientific programmes committees. Currently he is the head of Unit at INESC TEC (applied research Institute - formerly Inesc Porto).

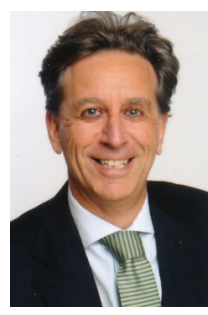

Andrea Vinelli, PhD, is a professor of Operations and Supply Chain Management and service Operations Management at the Department of Engineering \& Management at the University of Padova, Italy. He is the Dean of the Council of Engineering \& Management at the University of Padova, President of the Alumni Association of the University of Padova, President of the Italian Association of Engineering \& Management (AilG), Director of the MBA Programme at the CUOA Business School, Italy. He is a member of the Rector's Commission for Image and Ranking of the University of Padova, member of the Board of the School of Engineering, University of Padova, member of the Editorial Board of the International Journal of Operations and Production Management. His research and consulting interests lie in the areas of operations strategies, supply networks and supply chain management, with a specific expertise in the fashion industry, and on those topics he published in top management international journals.

\section{ORCID}

Andrea Zangiacomi iD http://orcid.org/0000-0002-2298-8481

\section{References}

Adler, P. S. 2001. "Market, Hierarchy, and Trust: The Knowledge Economy and the Future of Capitalism." Organization Science 12 (2): 215-234.

Bastos, João, Valentina Franchini, Américo Azevedo, and Rosanna Fornasiero. 2012. "Collaborative Networks Model for Clothing and Footwear Business Sector." In Collaborative Networks in the Internet of Services, 349-359. Berlin, Heidelberg: Springer.

Berasategi, Luis, Joseba Arana, and Eduardo Castellano. 2011. "A Comprehensive Framework for Collaborative Networked Innovation." Production Planning \& Control 22 (5-6): 581-593.

Boer, C. R., and S. Dulio. 2007. Mass Customization and Footwear: Myth, Salvation or Reality? A Comprehensive Analysis of the Adoption of the Mass Customization Paradigm in Footwear, from the Perspective of EUROShoE Research Project. London: Springer-Verlag. 
Bruce, M., L. Daly, and N. Towers. 2004. "Lean or Agile - A Solution for Supply Chain Management in the Textiles and Clothing Industry?" International Journal of Operations \& Production Management 24 (1-2): 151-170.

Camarinha-Matos, L. M., and W. Picard, eds. 2008. Pervasive Collaborative Networks. vol. 283. Boston, MA: Springer.

Camarinha-Matos, L. M., X. Boucher, and H. Afsarmanesh. 2010. “Collaborative Networks for a Sustainable World." 11th IFIP WG 5.5 Working Conference on Virtual Enterprises, Proceedings. US:Springer

Carter, Craig R., and Dale S. Rogers. 2008. "A Framework of Sustainable Supply Chain Management: Moving toward New Theory." International Journal of Physical Distribution \& Logistics Management 38 (5): 360-387.

Childerhouse, Paul, James Aitken, and Denis R. Towill. 2002. "Analysis and Design of Focused Demand Chains." Journal of Operations Management. 20 (6): 675-689.

Christiaanse, Ellen, and Kuldeep Kumar. 2000. "ICT-enabled Coordination of Dynamic Supply Webs." International Journal of Physical Distribution \& Logistics Management 30 (3/4): 268-285.

Christopher, M., H. Peck, and Denis Towill. 2006. "A Taxonomy for Selecting Global Supply Chain Strategies." The International Journal of Logistics Management 17 (2): 277-287.

De Treville, Suzanne, Roy D. Shapiro, and Ari-Pekka Hameri. 2004. "From Supply Chain to Demand Chain: The Role of Lead Time Reduction in Improving Demand Chain Performance." Journal of Operations Management 21 (6): 613-627.

Dyer, J. H., and H. Singh. 1998. "The Relational View: Cooperative Strategy and Source of Interorganizational Competitive Advantage." Academy of Management Review 23 (4): 660-679.

Eisenhardt, K. M. 1989. "Building Theories from Case Study Research." Academy of Management Review 14 (4): 532-550.

Eisenhardt, K. M., and M. E. Graebner. 2007. "Theory Building from Cases: Opportunities and Challenges." Academy of Management Journal 50 (1): 25-32.

Filos, E., and E. Banahan. 2001. "Towards the Smart Organization: An Emerging Organizational Paradigm and the Contribution of the European RTD Programs". Journal of Intelligent Manufacturing 12 (2): 101-119.

Fisher, M. L. 1997. "What is the Right Supply Chain for Your Product?" Harvard Business Review 73(4): 105-116.

Fornasiero, R., J. Bastos, A. Azevedo, E. Coscia, and A. Zangiacomi. 2013. "Collaborative Services for Customized Production in Networked Companies." In Collaborative Systems for Reindustrialization, 14th IFIP WG 5.5 Working Conference on Virtual Enterprises, PRO-VE 2013, Dresden, Germany, Proceedings Series: IFIP Advances in Information and Communication Technology, Vol. 408, edited by Luis M. Camarinha-Matos and Raimar J. Scherer, 363-372. Berlin, Heidelberg: Springer.

Fornasiero, R., and A. Zangiacomi. 2013. "A Structured Approach for Customised Production in SME Collaborative Networks." International Journal of Production Research 51 (7): 2110-2122.

Gimenez, C., T. van der Vaart, and D. P. van Donk. 2012. "Supply Chain Integration and Performance: The Moderating Effect of Supply
Complexity." International Journal of Operations \& Production Management 32 (5): 583-610.

Glaser, B., and A. Strauss. 1967. Grounded Theroy: The Discovery of Grounded Theory. Chicago, IL: Aldine.

Grefen, P., Mehandjiev, N., Kouvas, G., Weichhart, G., and Eshuis, R. 2009. "Dynamic Business Network Process Management in Instant Virtual Enterprises." Computers in Industry 60: 86-103.

Lee, H. L. 2004. "The Triple-A Supply Chain." Harvard Business Review 82 (10): 102-112.

Loss, L., and S. Crave. 2011. "Agile Business Models: An Approach to Support Collaborative Networks." Production Planning \& Control 22 (5-6): 571-580.

Nambisan, S. 2002. "Designing Virtual Customer Environments for New Product Development: Toward a Theory." Academy of Management Review 27 (3): 392-413.

Osterwalder, A., and Y. Pigneur. 2010. Business Model Generation - A Handbook for Visionaries, Game Changers, and Challengers. Hoboken, NJ: Wiley.

Pagell, M. 2004. "Understanding the Factors That Enable and Inhibit the Integration of Operations, Purchasing and Logistics." Journal of Operations Management 22 (5): 459-487.

Piller, F., and M. Tseng. 2003. New Directions for Mass Customization. The Customer Centric Enterprise. Advances in Mass Customisation. Springer.

Romero, D., and A. Molina. 2009. "VO Breeding Environments and Virtual Organizations Integral Business Process Management Framework." Information Systems Frontiers 11 (5): 569-597.

Romero, D., and A. Molina. 2011. "Collaborative Networked Organisations and Customer Communities: Value Co-creation and Co-innovation in the Networking Era." Production Planning \& Control 22 (5-6): 447-472.

Romero, D., A. Molina, and L. M. Camarinha-Matos. 2011. "Co-innovation and Collaborative Networks." Production Planning \& Control 22 (5-6): 445-446.

SCC (Supply Chain Council) 2010. "Supply Chain Operations Reference $\left(\mathrm{SCOR}^{\oplus}\right)$ Model Overview - Version 10.0." Accessed July 24, 2013. http:// www.apics.org/sites/apics-supply-chain-council/frameworks/scor

Seuring, Stefan, and Martin Müller. 2008. "From a Literature Review to a Conceptual Framework for Sustainable Supply Chain Management." Journal of Cleaner Production 16 (15): 1699-1710.

VRM. 2007. "Introduction to the Value Chain Reference Model and the BPTF" [online]. The Value Chain Group. Accessed July 24, 2013. http://www. value-chain.org/framework/value-reference-model

Yeung, H. T., T. M. Choi, and C. H. Chiu. 2010. "Innovative Mass Customization in the Fashion Industry." International Handbooks on Information Systems: 423-454.

Yin, R. K. 1994. Case Study Research. Design and Methods. Thousand Oaks, CA: Sage.

Zhang, X., D. P. van Donk, and T. van der Vaart. 2011. “Does ICT Influence Supply Chain Management and Performance? A Review of Survey-Based Research." International Journal of Operations \& Production Management 31 (11): 1215-1247. 